\title{
Duas elegias de Joaquim Cardozo
}

Elaine CRISTINA CINTRA*

MAXWELl AMORIM dos SANTOS**

\section{RESUMo}

O poeta pernambucano Joaquim Cardozo foi um dos autores modernos que mais contribuíram para uma revisão do gênero elegíaco em nossa lírica. Neste estudo, pretendeu-se analisar duas elegias do poeta, "Elegia para Benedito Monteiro" e "Para José Maria (de Albuquerque e Melo) ", voltadas especialmente a dois companheiros particularmente significativos em sua atividade poética, e que pertenciam a um grupo de artistas e intelectuais específico na década de 20 em Recife. Para tanto, recorreu-se a críticos que se dedicaram a estudar o poeta pernambucano e a poesia pernambucana moderna, como Souza Barros (1972), Merquior (1996), Correia (2018).

Palavras-chave: Poesia brasileira moderna; elegia; Joaquim Cardozo; Benedito Monteiro; José Maria de Albuquerque e Melo.

Elegia, luto e melancolia "Que linguagem há de vir desse pranto perfeito e derramado Nessa noite das noites, nessa noite sem mancha?" (CARDOZO, 2007, p. 234)

Dentre as formas poéticas líricas mais atrativas, a elegia se destaca como uma das prediletas dos autores de várias fases e nacionalidades. A

Professora no Departamento de Letras do Centro de Ciências Aplicadas e Educação da Universidade Federal da Paraíba/UFPB, João Pessoa, Mamanguape, Brasil; Docente colaboradora do Programa de Pós-Graduação em Estudos Literários, Universidade Federal de Uberlândia/UFU, Uberlândia, Minas Gerais, Brasil.

E-mail: elcintra@gmail.com

** Professor de português e inglês na Escola Estadual Indígena de Ensino Fundamental Professora Angelita Bezerra de Assis, Aldeia Silva de Belém, município de Rio Tinto, Paraíba, Brasil. E-mail:maxwell.005@hotmail.com 
poesia elegíaca está em todos os lugares e tempos, e resistiu às diferentes modulações que a lírica tomou durante as fases históricas, consolidando-se como uma das mais perfeitas expressões do gênero, tendo sido, inclusive, tomada várias vezes como um atributo seu.

A literatura brasileira não se esquivou do exercício da forma, retomando-a durante as fases literárias de maneira recorrente e significativa. Em seu Tratado de versificação, Olavo Bilac já atestava que "todos os poetas brasileiros têm mais ou menos escrito elegia" (BILAC; PASSOS, 1949, p. 129), e citava para demonstrar seu argumento o poema indianista "À minha filha”, de Gonçalves Dias, para, em seguida, lembrar a homenagem póstuma feita por Machado de Assis a este autor, em "À morte de Gonçalves Dias”. Nada mais propício do que tomar as citações de Bilac \& Passos como exemplares do gênero, uma vez que testemunham duas vertentes clássicas do estilo elegíaco que a tradição sagrou: em Gonçalves Dias, o lamento doloroso pela ausência de alguém ou algo valioso ao poeta; no poema de Machado de Assis, a homenagem lutuosa a um morto. A elegia abarcaria, então, em sua maneira tradicional mais antiga, o luto, e nas expressões mais modernas, a melancolia.

De lá para cá, os poetas nacionais se incumbiram de dar continuidade ao gênero com mestria, e autores importantes como Manuel Bandeira, Cecília Meireles, Carlos Drummond de Andrade, Vinícius de Moraes, Hilda Hilst, entre outros, experimentaram e trouxeram à elegia brasileira diversas contribuições. Nos autores supracitados, mais do que o exercício desse gênero poético, a elegia se tornou um dos pontos altos de suas obras, o que podemos facilmente demonstrar ao aludir, como exemplo, às elegias de Mar absoluto de Cecília Meireles (1945), livro que consolidará sua fase madura; ou às Cinco elegias, de Vinícius de Moraes (1943), também marco decisivo em sua poética, as quais serão retomadas por Hilda Hilst em Roteiro do silêncio (1959). Carlos Drummond de Andrade, que, mesmo com a contenção e racionalidade de sua expressão emocional não se esquivou de experimentar essa forma, realizou uma das mais contundentes elegias da poesia brasileira moderna, a "Elegia 1938”, poema publicado em Sentimento do mundo (1940), que imprime o 
sentimento de desolação e desconsolo absolutos em um mundo de guerra. Manuel Bandeira, por sua vez, é o poeta elegíaco mais pronunciado do período, e talvez de toda a literatura brasileira, não somente pelos vários exercícios do gênero que pululam em sua obra, mas também pela dicção elegíaca que percorre quase toda sua lírica. ${ }^{1}$

Neste momento, torna-se pertinente direcionar nosso olhar para o poeta pernambucano Joaquim Cardozo, que cotejou tal forma lírica em modos e percepções variados, os quais evidenciaram uma das particularidades de seu estilo, a melancolia, característica destacada por alguns de seus principais leitores, como Merquior (1996), crítico que analisou a "Canção elegíaca", apontando para tal modulação. Para o autor, Cardozo exemplifica com maestria a relação canção e melancolia:

Com efeito, a melancolia induz ao canto. A consciência sem projeto que é o melancólico tende a encontrar uma compensação para sua inércia na canção. E a ambígua manifestação do ânimo merencóreo, a um só tempo errante e prisioneiro, cativo e vagabundo, escolhe na canção a forma de traduzir-se. (MERQUIOR, 1996, p. 18).

Sem a esperança no futuro, o melancólico emoldura em seu canto a possibilidade mais conexa de se fazer inscrever. Merquior, no entanto, alerta que esse exercício de expressão virá através da ordem e da disciplina na arte, até mesmo de uma impessoalidade, uma vez que o melancólico reconhece os valores e práticas artísticas, nas quais a racionalidade organiza o ato comunicativo, pois, "Este, afinal, é o único projeto permitido ao melancólico, ao homem sem projeto: a superação pela arte. $\mathrm{O}$ puro e incontaminado triunfo do canto - e nada mais." (MERQUIOR, 1996, p. 19).

A conjunção entre um temperamento melancólico e um estado de consciência do exercício formal levado a extremos será renitente na poesia

Dentro desta perspectiva, Yudith Rosenbaum (2002) escreveu um interessante estudo sobre o poeta de Pasárgada: Manuel Bandeira: uma poesia da ausência. A autora, que acredita ser justamente na estetização das perdas que se dá a espinha dorsal do processo criativo de Bandeira, dedica uma parte do livro a analisar como este procedimento ocorre nas elegias do poeta. 
de Joaquim Cardozo, tornando o estilo elegíaco um de seus pilares. São vários os poemas em que a ausência excruciante, ou a pungente consciência subjetiva de desolação irremediável modulam-se no resgate da tradição elegíaca, como no poema "Só", exemplar lírico de uma solidão aguda à maneira de Antônio Nobre, ou "Poema", que herdou da elegia latina a dor lacerante da ausência erótica. No entanto, é preciso notar que, mais do que essas duas orientações, a dicção elegíaca em Cardozo também se emoldura em um incansável exercício formal, que busca ritmos, imagens e usos inusitados de categorias gramaticais, tensionando a emoção pungente com a lucidez da consciência do fazer poético.

A elegia não se afigura em Cardozo somente na dicção e no tom, mas também na remissão direta ao gênero, pois o autor cultivou a forma de maneira esporádica, porém persistente do início ao fim de sua atividade poética. O livro Poemas, publicado em homenagem a seus 50 anos em 1947, já apresentava ao leitor duas elegias importantes, "Elegia para Benedito Monteiro", talvez a primeira a ser escrita, tendo em vista que o amigo do autor morrera em 1926; e a "Elegia para os que ficaram na sombra do mar", que traz abaixo do poema a inscrição "Praia do Farol, Olinda, 1937", sinalizando para o intervalo de 10 anos da primeira.

O livro seguinte do autor, Signo estrelado, que veio a termo em 1960, apresenta um subitem chamado "Elegias", no qual o autor fez constar quatro poemas: "Canto do homem marcado", "Cemitério da infância”, "Canção elegíaca” e "Elegia para Maria Alves”, uma das mais encantadoras do poeta, a qual remete ao bucolismo da elegia romana, imprimindo ao poema uma delicadeza e leveza inusitadas ao gênero. $\mathrm{O}$ texto foi de fato publicado inicialmente na revista Para todos, em 1957, o que demonstra a inserção, neste momento, de Cardozo na vida cultural do Rio de Janeiro, cidade para onde se mudou em 1940, motivado por perseguição política. Em 1997, este poema, juntamente com “Cemitério da infância”, foram traduzidos para o inglês pela poeta americana Elizabeth Bishop (1972), em sua An Anthology of twentieth-century brazilian poetry. $\mathrm{O}$ fato de Bishop ter escolhido exatamente duas elegias para evidenciar a poesia cardoziana 
em sua antologia, no mínimo, testemunha o impacto com que tal gênero atingiu os leitores de sua lírica.

Também é na década de 1950 que Cardozo publica aquela que seria sua elegia mais conhecida, Prelúdio e elegia de uma despedida(1952), pela Editora Hipocampo, em edição com somente 116 exemplares autenticados pelo autor, composta a mão, com ilustração de José Pedrosa, tendo sido republicada no livro Trivium (1970), na revista Módulo, número 26, em 1961, e no número 52, em 1979.0 poema, dividido em três partes, traz ao final, nas anotações do autor, a informação de que esta elegia foi realizada para ser declamada a quatro vozes, contaminando o texto lírico com o estilo dramático. $\mathrm{O}$ tom do poema também se aproximará do gênero dramático no descomedimento pungente metaforizado pela noite e seus vieses imagéticos. A elegia se faz aqui em um grau máximo de desolação, ou melhor, no registro da queda, na "presença unânime da Queda" (CARDOZO, 2007, p. 237). O poema, um dos mais belos do autor e da literatura brasileira, é um exemplar perfeito da total desesperança e irreparável perdição que a elegia moderna expressa.

Na década de 1970, próximo a sua morte, o autor volta à elegia, não somente em "Elegia dos pássaros voando", publicado em Interior da matéria, em 1975, mas também com vários poemas dedicados a amigos e companheiros falecidos. A elegia cardoziana assume, na ocasião, o tom de despedida a um morto que vigorou no gênero em sua expressão inicial na literatura greco-romana, homenageando, na expressão lutuosa, aqueles que partiram. Em 1976, o Jornal do commercio, em Recife publica um editorial chamado "Elegias inéditas", que constam os seguintes poemas: "Para José Maria (de Albuquerque e Melo) ", "Rodrigo, Kruls", "Para Manuel Bandeira", "Augusto e Sarah", e "Augusto no Rio". Curiosamente, nenhum dos poemas listados no grupo "Elegias inéditas" trazem assinalam no título o gênero, sendo, no entanto, ironicamente aqueles que mais se aproximam, das elegias cardozianas, da tradição desta forma. Os poemas, publicados postumamente em periódicos e jornais, foram reunidos no volume da Poesia completa e prosa da Editora Nova Aguilar na seção "Outros poemas”, e vem marcados por movimentos narrativos que 
rememoram encontros e vivências de amigos de uma geração de artistas e intelectuais que foram decisivos em diferentes fases da vida do autor. Neste momento, próximo à morte, o octogenário poeta faz um balanço afetuoso de seus amigos que já haviam partido, e utiliza o gênero para nos deixar um testemunho poético dessas relações que foram vitais para a literatura da época.

Como se vê, são muitos os vieses que a elegia toma neste autor, e que demandam um olhar crítico mais demorado. No entanto, este estudo pretende destacar especialmente duas elegias de Joaquim Cardozo, mais especificamente os poemas voltados a Benedito Monteiro e a José Maria de Albuquerque e Melo, amigos e companheiros de Recife nos anos 20, que fizeram parte não somente de seu restrito círculo íntimo, mas também de sua história poética e intelectual. A menção a tais parcerias que foram particularmente significativas no início de sua atividade poética permite ao leitor desses poemas entender como o autor se utilizou do gênero elegíaco para traçar a sua presença no panorama cultural recifense da década de 1920 através da remissão aos dois amigos daquela época.

Da mesma forma, será possível entender como a configuração poética se constrói nos dois textos que apresentam ao menos 50 anos de distância um do outro, tendo sido o primeiro escrito na juventude do autor, e o segundo em sua maturidade, apesar de ambos se referirem a uma época específica de sua vida, como dito acima. Desse modo, a ênfase nessas duas elegias encaminha a discussão para um momento pessoal, histórico e estético específico assaz fundamental para a formação poética do autor, em duas dimensões.

Diante dessa necessária perspectiva contextual, outro posicionamento teórico se levanta. Uma das questões mais complexas do gênero elegíaco, que está implícita em sua gênese, é a sua relação com a autobiografia. Nas literaturas clássicas, uma das características da elegia que mais a diferenciava da epopeia, era a ênfase na figura do poeta, que ia a público para falar de suas questões mais individuais, como seus pensamentos e seus sentimentos melancólicos, como medos, anseios e tristezas, para, ao final, modular sentenças e máximas morais que levariam 
os ouvintes a um ensinamento sobre como suportar os revezes da fortuna. Da mesma forma, a elegia se consolidou em seu aparato tradicional como um poema que evidenciava uma pessoa do círculo de conhecidos do autor, avultando a relação com as questões empíricas, o que se tornou, conforme menciona Vasconcellos (2016), um grande problema para os elegíacos eróticos romanos, os quais recorriam ao humor para diluir o perigo de exposição social, ao se referirem a pessoas nobres e muitas vezes até comprometidas.

Em Cardozo, suas elegias de fato são testemunhos expressivos de uma época e de um grupo, no entanto, é importante alertar para o fato de que, quando modulado em um texto poético, ou seja, literário, o trabalho linguístico-estilístico submete a realidade a um processo de ficcionalização que invariavelmente a recria e reinventa. Assim, os elementos autobiográficos permanecem submissos ao trabalho artístico. Dentro desta perspectiva, no caso específico da elegia, vale lembrar que Veyne (2015, p. 83) afirma: "a elegia é uma poesia pseudoautobiográfica, em que o poeta conspira com os leitores contra seu próprio Ego." Trazendo esta postulação para o estudo aqui proposto, caberia-nos, então, analisar como tal “pseudo-autobiografia” está inferida nos processos poéticos com que Joaquim Cardozo retoma este gênero nos poemas que escolhemos para ler, e como esta retomada sugere novas modulações para esta forma, indiciando algumas perspectivas assumidas por este autor diante das proposições de seu momento estético e histórico.

\section{A morte do amigo: "Elegia para Benedito Monteiro"}

No ângulo da parede, janela do desconhecido, Apareceste a meus olhos, nessa noite profunda.

Por que vieste dos extremos limites?

Vejo no teu rosto sereno o reflexo vazio dos teus olhos apagados,

Nos teus cabelos há vestígios das indomáveis ventanias

Que perturbam as paisagens inevitáveis,

E a tua roupa está cheia de sombra...

Mas, por que trazes na mão essa flor escarlate? 
Ao longo dos valados,

Das estradas reais iluminadas,

Das estradas que se estendem para além dos arrabaldes,

Limitando os jardins das gentes simples,

Ainda há cercas de papoulas.

Ainda há chuvas generosas,

Ainda há sinos mensageiros,

Ainda há chuvas de janeiro.

Sobre as cores estivais.

Sinos de domingos,

Sinos de aleluias,

Sinos de alegrias matinais.

De certo, lá fora, a luz do dia está nascendo

O dia mais uma vez surpreende as árvores,

Surpreende todas as formas,

Pois os galos guerreiros estão cantando ao longo dos subúrbios

[alheios.

Quanto pela tua presença descansei minha lembrança!

Aperta a minha mão, adeus, Benedito Monteiro!

(CARDOZO, 1947, p.57-58).

O poema "Elegia para Benedito Monteiro" evoca o poeta e amigo do autor que morreu em 1926, aos 26 anos de idade, devido a complicações relativas à esquizofrenia. Benedito Monteiro foi companheiro de infância e adolescência de Cardozo, e com ele montou o jornal $O$ arrabalde, primeira experiência editorial dos autores. Mais tarde, na década de 20, retomaram o contato ao frequentar ambos o Café Continental, na esquina da rua Lafaiete em Recife, local em que se reunia na época boa parte da intelligentsia recifense, e onde se discutiam as repercussões das notícias advindas da Europa. Nesta época, Benedito Monteiro e Joaquim Cardozo, 
animados pelas notícias que chegavam em revistas, livros e testemunhos, formulavam versos já modernos, e os recitavam para os íntimos.

A esquina da Lafaiete foi, então, o cenário ideal para debates políticos, para discussões sobre questões sociais, e para interlocuções artísticas. Era ali que se comentavam as novas tendências e publicações tanto nacionais quanto estrangeiras, e era ali que os autores liam suas escritas recentes. Segundo Souza Barros (1972, p. 209), "Os encontros tinham um sabor de 'cenáculo”, nome adotado pelo grupo, que passou a ser conhecido como "Cenáculo da Lafaiete”.

Mais do que amigos antigos, a relação dos dois poetas se dá também nas afinidades artísticas e intelectuais. Ambos foram poetas que despontaram em uma época de intensa renovação na poesia, sendo o neotrovadorismo nos versos de Benedito Monteiro um exemplo das novas possibilidades de se fazer poesia diante da persistência das expressões parnasianas na época, como Cardozo (apud BARROS,1972, p. 265) informa: "Nesta época estava Benedito impregnado de um conhecimento poético bastante distanciado do parnasianismo, pois a sua poesia se prendia a um neotrovadorismo onde apareciam certos usos verbais, em redondilha maior, ou mesmo sonetos."

Da mesma forma, os dois poetas aderiram ao uso de ciências não afeitas à sensibilidade lírica, como a contabilidade e as exatas, como é possível observar em "O poema da Bolsa"2 de Monteiro, em que os versos trazem à tona o pregão de valores, em uma construção poética que revela a beleza lírica que pode estar contida neste ambiente, impregnada

A bolsa de mercadorias. As oscilações do mercado. / A curva logarítmica da queda da arroba do açúcar. /Os magnatas sentados pelas mesas / esperando o pregão dos corretores /Os especuladores baixistas esperando vender a prazo / para recomprar os lucros. /Os especuladores altistas esperando comprar a três meses para revender depois. / Os negócios firmes altamente perigosos. /Os corretores, correntes elétricas entre as diferenças /de potencial da oferta e da procura/ Ah! A aristocracia dos senhores de engenho, /açúcar de 2 cruzados. / A democracia dos fornecedores de cana/ e donos de banguês, açúcar de 11\$600. /-11 horas! /-O pregão! /-Vendo 4.000 sacos de cristal a 12\$900/ para entrega em dezembro! /-Compro a 12\$000! /E a batalha incruenta está travada / com o derramamento de sangue loiro das esterlinas! (MONTEIRO apud BARROS, 1972, p. 273). 
principalmente na grandeza dos sons do local e nas curvas logarítmicas das oscilações de valores da cotação. Mais tarde, em "Visão do último trem subindo ao céu”, Cardozo se utilizará da física e da matemática, retomando a imagem do trem, elemento central na amizade dos poetas, para expressar uma realidade em colapso.

Assim também os dois autores aderiram já na década de 20 ao estilo moderno que ganhava a ascensão na época. Para Souza Barros (1972), Benedito Monteiro foi um dos poetas mais modernos que apareceram nos anos 20 em Pernambuco, opinião ratificada por Ascenso Ferreira que afirma ter sido este autor a maior influência de sua formação poética.

Benedito Monteiro era uma figura peculiar. Dotado de uma personalidade irreverente, cabelos longos ao vento, o poeta era um grande estudioso de literatura e para todos os lugares por onde andava, Benedito Monteiro sempre levava consigo poesias antigas e modernas como as de Verlaine, Baudelaire, Mallarmé, Apollinaire, Bréton e depois os modernistas do Sul, Sérgio Milliet, Oswald de Andrade e Mário de Andrade, Luís Aranha. Infelizmente, muitas das poesias de Benedito foram perdidas, principalmente por ele não as guardar e sempre as escrever em pedaços de guardanapos, e até mesmo em caixas de fósforo, vindo, inclusive a fumar alguns de seus versos.

A morte veio e levou Benedito Monteiro aos 26 anos de idade, abalando seus amigos e companheiros pelo inesperado do fato, o que pode ser conferido na nota de José Maria de Albuquerque e Melo publicada na Revista do Norte, que nos permite entender a dimensão do acontecimento:

Uma sequência ampla de vibrações. Sempre assim a vida de Benedito. Menino, a ouvir o chamado dos sinos das igrejas velhas de Goiana, rapaz, a se empolgar pelo que a ciência dos homens pode dar.

Um insaciável. Um eterno apaixonado da Investigação. Benedito viveu uma investigação. E o número que tão caracteristicamente soube incorporar a alguns de seus últimos poemas, de intensa e sincera sofreguidão, exerceu sobre Benedito permanente e interessantíssimo fascínio. Chegou até a satisfazer, por um instante, aquela grande ânsia de certeza que sempre o animou. Quase chegou a arrastá-lo às bordas 
de um ingrato materialismo. A matemática, porém, acentuou em Benedito o ímpeto das soluções satisfatórias. Ao lado da exatidão matemática, de cuja insuficiência para responder as íntimas interrogações, cada vez mais largas, logo se apercebeu, Benedito soube buscar aquela outra exatidão mais ampla, mais confortadora e ritmada.

Logo a encontrou.

Encontrou-a com a mesma facilidade com que, naquelas suas boas caminhadas a pé, passo ligeiro, sacudindo os braços, a cabeleira muito sacudida pelo vento, ia encontrar, pelos povoados à beira das estradas brilhando de sol, doces capelas de brancas ou enegrecidas paredes e ornatos rústicos e ingênuos.

E Benedito pisou, por um instante as lajes do claustro de S. Francisco, diante daquelas cenas do GÊNESIS, em azulejos de brilho vivo.

Tempos de Páscoa. Diante do crucifixo, lá esteve de joelhos, na complexidade sublime da contrição. Complexidade cristã e sobrenatural.

E tudo que lhe pudesse seguir, Benedito desprezou, como se desprezam, às vezes, no discurso de operações matemáticas, certas quantidades infinitamente pequenas. Desprezou sob a convicção plena que lhe trouxera aquela eterna matemática mística, que, tão rapidamente, tão sinteticamente, o fizera resolver a eterna equação. (ALBUQUERQUE E MELO, 1926, p. 15).

A Revista do Norte, periódico em que Benedito Monteiro participou como autor de seis textos em prosa e cinco poemas, conforme Neroaldo Azevedo (1996), prestou tributo ao poeta consagrando-lhe um número em junho de 1926, que, além da publicação de um poema inédito de sua autoria, "As pedras", contou com artigos sobre de João Vasconcelos e José Maria C. de Vasconcelos e Melo que rememoraram sua obra e sua persona. Cardozo contribui com o volume não somente como um de seus editores, junto a José Maria de Vasconcelos e Melo e João Monteiro, como também com uma caricatura de Monteiro, na qual o cachimbo e os cabelos esvoaçantes do companheiro se evidenciam, em uma referência a seu espírito livre e rebelde, como também com um poema chamado "Velhas ruas", que como veremos, é significativo em relação ao contato com esse autor, e até mesmo, com o grupo da revista. 
Figura 1- Benedito Monteiro

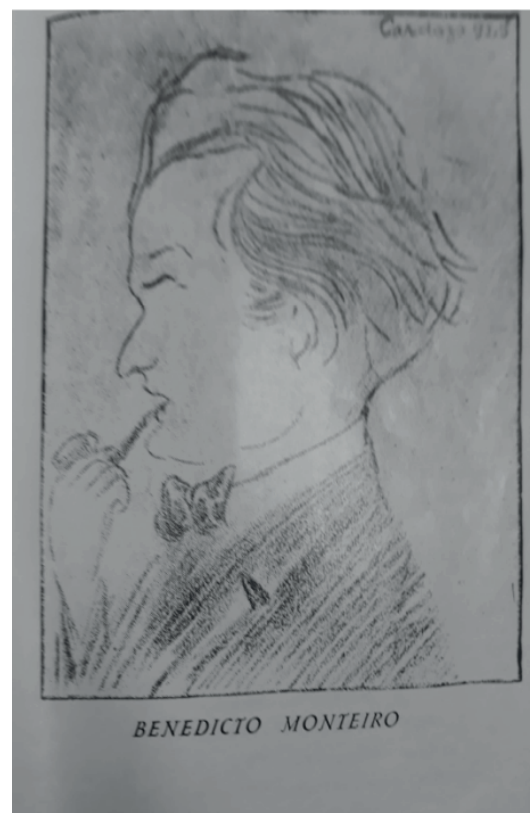

Fonte: CARDOZO (1926, p. 12).

Vinte anos após o falecimento do amigo, Joaquim Cardozo publica o poema “Elegia para Benedito Monteiro", apesar de Souza Barros (1972) admitir, em depoimento, que o lera meses após o passamento de Monteiro. ${ }^{3}$ A imagem central deste poema é a visita do fantasma de Monteiro ao eu lírico, a qual desencadeia no poeta a rememoração de vários momentos vividos em comunhão com seu dileto amigo de infância e juventude. A presença do fantasma, tão recorrente na poética de Cardozo, representa

3 No livro de Barros (1972), o autor registra, antes de transcrever o poema "Elegia para Benedito Monteiro":

Soube de sua morte, dias após, mergulhado que estava na distância próxima das arquitetadas conspirações da época. Com alguns amigos, abracei-me à saudade de uma presença que teimava em estar viva no meu subconsciente. Um desses amigos, e dos mais próximos, no desabafo da comum saudade, meses depois, me deu a ler cópia da [...]. ( p. 279).

Em seguida, Souza Barros transcreve a elegia de Cardozo para Monteiro aqui discutida. 
aqui o passado irrecuperável, mas ainda operante no presente, e, nesta elegia, imprime uma tocante nota de afeto e saudade, ao contrário do que ocorre em outros poemas do autor nos quais o elemento sobrenatural assombra o presente de maneira sombria e opressiva.

O poema é formado por versos livres em sete estrofes irregulares, e sem propriamente um esquema rímico, além do uso de uma linguagem coloquial. É interessante notar que esta elegia se distancia do formato clássico do gênero, pois abstém de se utilizar da copla elegíaca, formada tradicionalmente por um dístico de um hexâmetro e um pentâmetro, e também não acompanha as partes tradicionais da elegia, ou seja, o lamento pela perda, o louvor ao passado e a consolação em um futuro redentor. De fato, vê-se um arranjo original, pois o poema se destaca por algumas soluções formais que enfatizam a homenagem ao morto, como a quantidade de versos, 26, número exato de anos de Benedito Monteiro ao morrer e ano de sua morte (1926). Apesar disso, o nome do amigo só aparece duas vezes no decorrer de todo o poema: uma vez no título propriamente dito, e outra no último verso, desse modo, emoldurando o poema, tornando-se seu princípio e fim.

A construção poética evidencia três momentos essenciais que narram todo o percurso da visita fantasmal de Benedito Monteiro ao poeta, separadas por pontilhados. Em um primeiro momento, a noite propicia a aparição do fantasma do amigo morto, que, com olhos apagados e vazios, com a roupa cheia de sombra, vem visitar o poeta. $\mathrm{O}$ segundo momento é marcado pela ida ao passado através da memória, memória esta que faz parte das vivências de ambos os amigos. Por fim, volta-se ao presente lutuoso, e o poeta despede-se do amigo.

A primeira parte, composta pelas primeira e segunda estrofe, apresenta alguns procedimentos poéticos que serão matriciais em todo o poema, como o uso recorrente de substantivos concretos, como "parede", "janela”, "olhos", "rosto", “cabelos”, os quais, tencionados com adjetivos de caráter sobrenatural, fragilizam a materialidade de sua essência ao atribuirlhes a ideia do sobrenatural e irracional, prenunciando a atmosfera fantasmagórica que dominará o poema. Assim, por exemplo, no primeiro 
verso, em "No ângulo da parede", o substantivo "parede", transformado em locução adjetiva, vem contribuir com a ideia de obtusidade, uma realidade escorregadia e vulnerável que o tema demanda.

A sequência do verso, "janela do desconhecido", apresenta-se como um quiasma da imagem anterior, se considerarmos a ordem dos termos deste grupo semântico, pois "parede" era a segunda palavra da expressão e atuava como adjetivo, e, por sua vez, "janela”, que faz parte do campo semântico de parede, se torna o primeiro termo da sequência, em seu papel original de substantivo concreto. A "janela do desconhecido" é talvez a imagem chave do poema, uma vez que a adjetivação lhe concede o papel de intermedialidade entre a realidade concreta e o elemento sobrenatural, o portal para o mundo dos mortos, que permitirá a invasão no espaço ficcional e no poema do amigo morto, personagem central dessa elegia. Os outros adjetivos confirmarão essa obliquidade que tornam os substantivos concretos, representativos da realidade, em elementos do desconhecido, como nos exemplos a seguir: "noite profunda" (v.2), "reflexo vazio" (v.4), "olhos apagados" (v.4), "indomáveis ventanias” (v. 5), "paisagens inevitáveis" (v.6), roupa "cheia de sombra" (v.7), "flor escarlate" (v.8). Nota-se, então, que nessa primeira parte do poema, destinada a constituir a atmosfera ideal para o aparecimento do amigo morto, todos os versos propõem imagens com uma adjetivação que metamorfoseiam substantivos concretos em expressões do sobrenatural.

Outra questão a ser observada nos procedimentos poéticos desta parte é a assonância da vogal (e) que aparece 48 vezes, do título até a segunda estrofe, como em: "Elegia para Benedito Monteiro", "parede, janela do desconhecido", "Por que vieste dos extremos limites?", contaminando os versos com uma sonoridade fúnebre fantasmagórica, o som do sussurrar da noite profunda. Ademais, tal assonância reafirma a palavra chave do poema, "Benedito", na qual esta vogal se repete duas vezes.

Da mesma forma, outro recurso de repetição do som, a aliteração, contribui para emoldurar o cenário perfeito para a chegada do fantasma. No quinto verso, a aliteração do "v" em "vestígios, indomáveis, ventanias" desencadeia o som dos ventos que perpassaram a vida do fantasma. Tais 
ventanias, que lembram os longos cabelos ao vento de Benedito Monteiro, símbolo de sua essência livre e insubmissa, também são uma remissão às ventanias infernais da Comédia de Dante, ou à ambientação da morte ou das esferas do sobrenatural que foram perpetuadas na literatura ocidental.

$\mathrm{Na}$ segunda estrofe, composta por um só verso, o poeta interroga a figura fantasmal e destaca a flor escarlate que está em suas mãos, flor esta que possui um tom vermelho com uma matriz que pende para a cor laranja. A vermelhidão da flor desencadeia uma luz forte em meio a toda essa escuridão, e é por meio dessa luz que as imagens do passado vão vir à tona na próxima estrofe.

Se a primeira parte da construção imagética possui tons escuros de uma noite sombria e fantasmal, o clarão vermelho-alaranjado da imagem no verso único da segunda estrofe funciona como um dispositivo de intermediação entre o presente e o passado, e, por conseguinte, entre a morte e a vida. As cores do poema também se abrem em uma luz solar, e a noite se guarda para a lembrança de um passado feliz ao lado do amigo. As estradas são "iluminadas" (v.10), nos jardins há "cercas de papoulas" (v. 13), as chuvas são "generosas" (v.14), as cores são "estivais” (v. 17),os sinos são "mensageiros” (v. 15),"de domingo" (v.18), "de aleluias” (v. 19), "de alegrias matinais" (v.20). Percebe-se, então, que também aqui a adjetivação funciona como elemento essencial para a construção de uma atmosfera; neste caso, oposta à parte anterior, funcionando como um jogo de escuro/luz, que percorre o poema, no qual uma parte só se postula de maneira essencial a partir da outra, oposta, mas simétrica e complementar a ela. Uma síntese possível e hipotética só será entrevista na parte terceira e final.

É importante lembrar que o uso singular da adjetivação na poesia de Joaquim Cardozo já foi notado por alguns críticos, como Éverton Correia, que comenta ser esse "um índice de sua expressão e traço de seu estilo" (CORREIA, 2018, p. 225). Para esse autor, o adjetivo é neste poeta, "objeto de um uso imprevisto, inusitado e expansivo do entendimento da linguagem, radicado mais na sua função do que na descrição gramatical, 
como se contradissesse a abstração classificatória da linguagem [...]” (p. 225).

Esta parte realiza em um modo mais amplo a aderência aos procedimentos tradicionais da elegia, a começar pela narração dos feitos do morto, na recorrência à memória para trazer ao presente aquele cuja ausência se lamenta. Também neste segundo momento, nota-se outro recurso bastante comum na tradição da elegia, a repetição, aqui formulada nas anáforas dos versos 13, 14, 15 e 16: "Ainda há cercas de papoulas. // Ainda há chuvas generosas, / Ainda há sinos mensageiros/ Ainda há chuvas de janeiro. ", únicos versos com uma regularidade métrica, no caso, o octossílabo; e dos versos 18, 19 e 20, os quais pelo afastamento gráfico dos versos funcionam como um refrão, a badalar com sua musicalidade aberta na assonância do "a" e "i" a leveza de um dia perfeito: "Sinos de domingos, / Sinos de aleluias, Sinos de alegrias matinais”. Aberto o portal do desconhecido, é possível, então, voltar aos tempos felizes em que os companheiros passeavam por Recife e Olinda.

\section{EM QUE RECIFE VIVES AINDA?}

As longas caminhadas em grupo eram bastante comuns entre Cardozo e seus companheiros da Revista do Norte. Em seu depoimento ao livro de Souza Barros (1972), o autor de "Elegia para Benedito Monteiro" assim descreve o periódico:

À Revista do Norte estão associados quatro aspectos curiosos: O primeiro, a grande preocupação pelo aspecto da Revista, pouco importava o seu dia de saída, aspecto gráfico, que produziu talvez, na época, as mais belas páginas da arte de impressão do Brasil; o segundo aspecto eram as peregrinações do grupo da Revista, as visitas, as caminhadas que nos levavam às vezes, tarde da noite, a Olinda ou a Igaraçu, onde contemplávamos os conventos e igrejas, alguns em ruínas; o terceiro, as reuniões noturnas no Café Continental, onde se comentava nas conversas sobre tudo o que se passava durante o dia, assim como era de onde saíamos para frequentar os concertos no Santa Isabel; o quar- 
to, era a reunião que se fazia, aos sábados, na própria oficina de José Maria de Albuquerque e Melo, para as quais mandou ele construir um pequeno edifício próprio (essas reuniões, aos sábados, no sítio de José Maria ou, melhor, do seu pai, o grande jornalista Manuel Caitano: sítio arborizadíssimo, onde havia pés de ubaias, mangueiras, cajueiros, grandes jaqueiras, que, às vezes, produziam os seus frutos junto às sapopembas, raízes próximas ao tronco; dessas árvores frutíferas a mais importante era uma velha mangueira: mangueira Primavera, da estirpe mangueira Jasmim, e que tinha a sua origem nas velhas mangueiras da ilha de Itamaracá.) (CARDOZO apud BARROS, 1972, p. 145-146).

Motivados pela proposta de preservação da tradição regional, o grupo propunha-se a conhecer a região em todos os seus meandros, como se pode ver em outra elegia do autor, esta dedicada a José Maria Carneiro de Albuquerque e Melo, editor chefe da Revista do Norte, e também companheiro desta fase.

"Para José Maria"

(de Albuquerque e Melo)

José Maria! José Maria! Nós dois vivemos

Uma vida sonhada e esquecida,

Uma vida passada, provada e perdida

Entre os velhos Recifes e as velhas pontes.

Caminhamos muitas vezes

Pelo istmo que vai do Recife a Olinda;

Quantas vezes estivemos em Gaibu

E depois visitamos Nazaré do Cabo

-Do Cabo de Santo Agostinho

-De Santo Agostinho.

Ainda sinto que te ouço

Mas não te vejo mais

Onde estás agora? 
Desembarcamos uma vez na Ilha de Santo Aleixo

Partindo da foz do rio Serinhaém

Para vermos de perto a ilha isolada e deserta.

Continuam até hoje frutificando

As mangueiras da Ilha de Itamaracá

Mangas Jasmim, mangas Carlota e Primavera.

Lembro a excursão que fizeste

Caminhando a pé até Goiana:

Viajava contigo Benedito Monteiro.

Na Ilha de Itamaracá, quantas vezes

Visitamos o Forte Orange.

-Vínhamos sempre navegando

Dentro de um barco a vela

Ao longo do canal da Ilha

Até Itapissuma, bem perto de Goiana.

Na praia de Tambaú, Paraíba do Norte,

Almoçávamos, às vezes, sopa de cabeça de peixe;

E subíamos a colina do Cabo Branco

Penetrando mar adentro.

Tudo agora, Zé Maria, continua como sempre.

Por todos os lugares onde passamos

Lembramos a tua companhia,

Sempre frequente em nossos passeios.

-Sei que não te vejo

Mas parece-me que estás perto de mim.

Em que Recife

Em que Istmo

Em que praia Formosa

Em que Rocha aflorante

Nas águas cor de anil,

Vives ainda? 
Adeus, Zé Maria!

São seis horas da tarde;

Os sinos das igrejas estão soando

Ave! Maria!

(CARDOZO, 2007, p. 376-377).

O primeiro detalhe que se faz notar neste poema é seu título. Se a elegia anterior mencionava nome e sobrenome do sujeito a ser referido, "Benedito Monteiro", nesta segunda, o sobrenome "de Albuquerque e Melo" aparece entre parênteses, como se fosse um adendo para esclarecer a identidade do sujeito em questão. Ora, não se pode passar despercebido o fato de que o sobrenome "de Albuquerque e Melo" carrega o peso de uma tradição familiar na região pernambucana, mas, entre parênteses, acaba por destacar o íntimo "José Maria", confirmando o tom afetuoso que o poema pretende impor.

José Maria de Albuquerque e Melo foi professor de História da Arte na Escola de Belas-Artes de Pernambuco, e ficou conhecido não somente por dirigir a Revista do Norte, mas também por ser um exímio tipógrafo, que se dedicava com esmero aos volumes que organizava, e uma qualidade editorial reconhecida pelo poeta João Cabral de Melo Neto, que também se aventurou à tipografia, como se pode verificar em suas cartas a Bandeira reunidas por Flora Süssekind (2001). O editor, como relatou Cardozo a Souza Barros, organizava caminhadas a pé, em que o grupo percorria monumentos artísticos e históricos da região.

No poema a José Maria, as longas e constantes caminhadas do grupo são descritas de maneira mais pormenorizada, e a elegia funciona, além do registro do doloroso sentimento de perda de um momento idílico que já passou, como um processo de documentação dos roteiros percorridos por aqueles jovens artistas e intelectuais recifenses.

$\mathrm{Na}$ leitura deste poema, saltam aos olhos as diferenças estruturais das duas peças poéticas. Se na primeira elegia a presença do morto, tanto em sua visitação fantasmal como na recorrência da memória, é mais 
significativa que sua ausência, nessa segunda, é a ausência que é clamada, especialmente nas interrogações que são feitas quanto ao local presente do amigo evocado, quanto nas reiteradas afirmações do eu lírico de que não vê mais o amigo: "Ainda sinto que te ouço/ Mas não te vejo mais/ Onde estás agora?" (v. 11, 12 e 13); "Sei que não te vejo/ Mas parece-me que estás perto de mim." (v. 37 e 38). Por outro lado, é nesse jogo de ausência e presença, em que o amigo morto se faz presente ainda, que os dois poemas se conformam, jogo este que é uma grande metáfora da presença-ausência da linguagem poética, no movimento incansável de seus signos e sentidos.

$\mathrm{Na}$ divisão em partes e na distribuição de estrofes e versos, as duas elegias se diferenciam de maneira drástica. "Para José Maria (de Albuquerque e Melo) " estrutura-se como uma caminhada, que, vezes por outra, é interrompida por alguma distração, ou melhor, uma digressão, como toda caminhada aleatória, como era aquelas que os jovens escritores pernambucanos faziam. Os 48 versos divididos em 13 estrofes se dispõem na seguinte ordem: na primeira parte, v. 1 a 4, dá-se a evocação do amigo morto e da história entre ele e o poeta. Na segunda parte, v. 5 a 44, o poeta rememora em uma narração repleta de referências a paisagens pernambucanas e paraibanas visitadas pelos companheiros na segunda estrofe. Esta seção, mais longa que as outras, traz três estrofes digressivas: a 3..$^{\text {a }}$ estrofe, v. 11 a 13, a qual indaga sobre o local atual do amigo; a 5. ${ }^{\mathrm{a}}$ estrofe, v. 17 a 19, que retorna ao passado para informar ao amigo que os elementos da paisagem continuam no presente como antes, movimento este que voltará na 10. ${ }^{\mathrm{a}}$ estrofe, responsável por finalizar a narrativa dos passeios, e registrar que o amigo é lembrado por todos. É interessante notar que nesta $5^{\text {a }}$. estrofe, o poeta comenta as mangueiras de Itamaracá, "Continuam até hoje frutificando/ As mangueiras da Ilha de Itamaracá/ Mangas, Jasmins, mangas Carlota e Primavera” (v. 17 a 19), também referidas no depoimento citado acima, trazendo uma vez mais, um elemento passível de conferição, e ampliando o jogo autobiografia/ficção que a elegia propõe. A $11 .^{\mathrm{a}}$ estrofe, também digressiva, repete e amplia

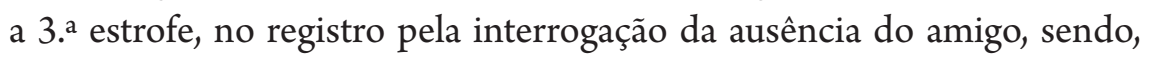


de fato, uma passagem para a terceira e última parte, em que o autor se despede do amigo, ao soar da Ave Maria, ou seja, às 6horas da tarde.

Eis, pois, uma semelhança com a elegia anterior: os dois poemas se constituem como rituais de despedida, e terminam com o "adeus" do eu lírico aos amigos mortos. No entanto, a temporalidade de tais despedidas é diferente, pode-se até dizer oposta, e isto será deveras significativo para marcar o tom do poema. Em "Para José Maria”,o adeus se dá no por do sol, nas "Ave-Marias", que no trocadilho faz ressoar em repetição o "Adeus, Zé Maria!" no trocadilho "Ave! Maria!" do último verso, em que o ponto de exclamação desloca a saudação da santa para o amigo, quase que santificando o amigo, conhecido por, em vida, ter sido extremamente devoto e religioso.

Por sua vez, na "Elegia para Benedito Monteiro", com o nascer do dia, a noite fantasmal desaparece, e o presente ressurge novamente, sobrepondo-se aos fantasmas da memória e da morte. A figura do galo, representativa do novo tempo, surge no verso 24 , que, aliás, é o mais longo de todo o poema com 20 sílabas poéticas, reproduzindo o alcance do cantar do galo que consegue atingir longas distâncias. $\mathrm{O}$ que resta a fazer é dar uma última e fraterna despedida ao seu amigo Benedito Monteiro em um dos mais belos e pungentes versos da literatura brasileira: "Quanto pela tua presença descansei minha lembrança! / Aperta a minha mão, adeus, Benedito Monteiro." (v. 25 e v. 26). No aperto de mão, símbolo de um acordo tácito entre homens que se respeitam, fecha-se o ciclo do luto pela ausência do amigo.

\section{CONSIDERAÇÕES FINAIS}

Isto posto, cabe dizer que nos dois poemas, a escrita entranhada do elemento autobiográfico e evocativo da memória, revitaliza a elegia em duas modulações praticamente opostas, mas, de uma maneira peculiar, complementares. Na "Elegia para Benedito Monteiro", Cardozo mantém o estilo noturno e grave, até mesmo sombrio, de suas primeiras elegias, com tons fantasmagóricos e até dramáticos. Em "Para José Maria (de Albuquerque Melo) ", a atmosfera é solar, diurna, na qual a evocação da memória é predominante, apesar das angustiantes inserções de um presente marcado pela ausência e saudade. Nela, a digressão é o procedimento que 
contamina a elegia de um rastro do drama, uma vez que realiza no poema uma politonia, voz outra que se alterna com a voz principal de um lírico narrador. Em ambas, a contaminação dos gêneros é pautada como um exercício de subversão e reinvenção do modelo clássico, ao mesmo tempo em que reafirma a densidade e intensidade da emoção que percorre toda a poética de Cardozo, sempre à beira do descomedimento e do patético.

Da mesma forma, as duas elegias referidas confirmam o traço moderno que nega o suposto consolo e projeção para o futuro que o gênero prevê em sua modulação tradicional. Em ambos os textos, a elegia apenas constata as lacunas e os vazios da existência moderna, que não se solucionam mas encontram na expressão artística, uma suposta organização estética, e assim, o sentimento melancólico que inebria a obra deste autor não se resolve, mas mantém-se em um registro alto, e, como tal, revigorante.

As duas elegias de Joaquim Cardozo, então, atestam uma poesia em que a tensão emocional extrema é emoldurada por um trabalho racional e lúcido na forma, na simultânea recorrência e desmonte da estrutura tradicional, em uma relação ambígua de insubordinação e obediência, mas principalmente de consciência dos processos que levam os procedimentos poéticos a causar efeitos expressivos, ao mesmo tempo em que, na complexidade de sua construção, testemunham momentos específicos da vida do autor, em seu momento de iniciação como poeta.

Two elegies of Joaquim Cardozo

AbStract

Elegy, a genre that has received a special prominence in modern Brazilian poetry, presents in the twentieth century a melancholic, desolate subject with no hope of comfort in the future. This assumption can be noticed in Joaquim Cardozo, author of poems with a highly melancholic and elegiac diction. The aim of this study was to analyze two elegies of this poet, "Elegia para Benedito Monteiro" and "Para José Maria (de Albuquerque e Melo)", especially directed to two fellows who were particularly significant in their poetic activity, and who belonged to 
a specific group of artists and intellectuals in the 1920s in Recife. In a general way, this review proposed to discuss such elegies from two perspectives: in the first, we sought to understand the poetic processes with which Cardozo takes this genre, and how it reshapes new modulations for the form, indicating the perspectives assumed by him face the propositions of his aesthetic and historical moment; in the second, we tried to trace how such elegies document a group that still deserves to be better discussed by the literary studies. In order to do so, some literary critics were used to study this poet from Pernambuco and the modern poetry from this place, such as Souza Barros (1972), Merquior (1996), Correia (2018).

KeYwords: Modern brazilian poetry; elegy; Joaquim Cardozo; Benedito Monteiro; José Maria de Albuquerque e Melo.

Dos elegías de Joaquim CARdozo

RESUMEN

Joaquim Cardozo, poeta de Pernambuco, fue uno de los autores modernos que más contribuyó a la revisión del género elegíaco en nuestra letra. En este artículo, se analizaron dos elegías del poeta, "Elegia para Benedito Monteiro" y "Para José Maria (de Albuquerque e Melo)", centrándose especialmente en dos compañeros que fueron particularmente significativos en su actividad poética, y que pertenecían a um grupo de Artistas e intelectuales de los anõs veinte en Recife. Para ello, recurrimos a críticos que se dedicaron a estudiar el poeta de Pernambuco y la poesía moderna de esto lugar, como Souza Barros (1972), Merquior (1996), Correia (2018).

Palabras clave: Poesía brasileña moderna; elegía; Joaquim Cardozo; Benedito Monteiro; José Maria de Albuquerque e Melo.

REFERÊNCIAS

ALBUQUERQUE E MELO, José Maria Cavalcanti. Benedito Monteiro. Revista do Norte,Recife, Fase 2, n. 1, p. 15 jun. 1926. 
AZEVEDO, Neroaldo Pontes. Modernismo e regionalismo: os anos 20 em Pernambuco. Recife-PE; João Pessoa-PB: Editora da Universidade Federal de Pernambuco; Editora da Universidade Federal da Paraíba, 1996.

BARROS, Souza. A década 20 em Pernambuco. Rio de Janeiro: Paralelo, 1972.

BILAC, Olavo; PASSOS, Guimarães. Tratado de versificação. Rio de Janeiro: Francisco Alves, 1949.

BISHOP, Elizabeth. BRASIL, Emanuel (Org.). Na anthology of twentieth-century brazilian poetry. Middletown, Connecticut: Wesleyan University Press, 1972.

CARDOZO, Joaquim. Benedito Nunes (caricatura). Revista do Norte, Fase 2, Recife, n. 1, p. 12 jun. 1926.

.Poemas. Rio de Janeiro: Agir, 1947.

. Poesia completa e prosa. Rio de Janeiro: Nova Aguilar, 2007.

. Poesias completas. 2.ed. Rio de Janeiro: Civilização brasileira, 1979.

CORRÊA, Alamir Aquino. Elegia e musicalidade em Os mortos, de Ivan Junqueira. Ipotesi, v. 19, n. 1, p. 64-77, jan./jun. 2015.

CORREIA, Éverton Barbosa. Dicção individual e intervenção pública em "Três sonetos positivos" de Joaquim Cardozo. Letras de hoje: estudos e debates em linguística, literatura e língua portuguesa, v. 53, n. 2, p. 223-231, abr./jun. 2018.

MERQUIOR, José Guilherme. Uma canção de Cardozo. In: . Razão do poema. Rio de Janeiro: Topbooks, 1996. p. 17-35.

ROSENBAUM, Yudith. Manuel Bandeira. Uma poesia de ausência. 2. ed. São Paulo: Editora da Universidade de São Paulo, 2002.

SÜSSEKIND, Flora (Org.). Correspondência de Cabral com Bandeira e Drummond. Rio de Janeiro: Nova Fronteira; Edições Casa de Rui Barbosa, 2001.

VEYNE, Paul. Elegia erótica romana. Tradução Mariana Echalar. São Paulo: Editora da UNESP, 2015.

Submetido em 30 de dezembro de 2018

Aceito em 10 de agosto de 2019

Publicado em 15 de outubro de 2019 